\title{
Instruction Design Model for Self-Paced ICT System E-Learning in an Organization
}

\author{
Ridi Ferdiana \\ Electrical Engineering and IT Department \\ Universitas Gadjah Mada \\ Yogyakarta, Indonesia
}

\author{
Obert Hoseanto \\ Partners in Learning Department \\ Microsoft Indonesia \\ Jakarta, Indonesia
}

\begin{abstract}
Adopting an Information Communication and Technology (ICT) system in an organization is somewhat challenging. User diversity, heavy workload, and different skill gap make the ICT adoption process slower. This research starts from a condition that a conventional ICT learning through short workshop and guidance book is not working well. This research proposes a model called ICT instruction design model (ICTIDM). This model provides fast track learning through integration between multimedia learning and self-paced hands-on E-learning. Through this case study, we discovered that the proposed model provides $27 \%$ rapid learning adoption rather than conventional learning model.
\end{abstract}

Keywords- ICT System Adoption; Learning Model; Multimedia Learning; E-learning; Instruction Design Model; Learning Plan.

\section{INTRODUCTION}

Good ICT system is not only about good software or a good hardware but it also need skilled users. After an ICT system is developed, it needs additional time for the system to be used by the user. The implementation phase in software engineering should make sure that the user feels comfortable to use the system.

The implementation phase in ICT system is done by doing several socialization activities such as training, hands-on workshop, coaching or even giving a grant for the users who use the system correctly. Tsui and Karam [16] mention several characteristics of good ICT system implementation which are:

- Readability: The software can be easily read and understood by the programmers.

- Maintainability: The code can be easily modified and maintained.

- Performance: All other things being equal, the implementation should produce code that performs as fast as possible.

- $\quad$ Traceability: All code elements should correspond to a design element. Code can be traced back to design.

- Correctness: The implementation should do what it is intended to do.

- Completeness: All of the system requirements are met.
However, these good implementation characteristics are only eligible when the users are digital literate and can use the system well. If the users lack digital literacy or unable to use the system, the good implementation only happened within the software team and not in the user's perspective.

An organization invests an ICT system to be used by the employees. It will not be a matter if the user of the ICT system is only a few (less than 10 users). However, the problem arises when the ICT system should be adopted for tens or hundreds of users.

This research starts from a real implementation problem in an organization called Alpha. Alpha is a government organization that works to enhance mathematic educators in Indonesia. Alpha implements an ICT collaboration system called Live@edu. Live@edu is a collaboration system developed by Microsoft for education institutions. It contains software which is:

- Email software.

- Online storage software.

- Instant messaging software.

- Personal Information Management software.

- Office Productivity software.

The software has more than five features. According to the Live@edu services page at http://bit.ly/liveateduservices , it shows that the services have 21 primary features. Additionally, half of the features are essential for business solution in the organization. These essential features should be acknowledged and used by the 50 users within two weeks.

The implementation team has done socialization activities through face-to-face discussion, full-day workshop, and delivered a user manual. The socialization activities received a good response with satisfaction index 8.5 (of scale 10). However, the organization management did not see a usage progress of the system and found several issues which are:

- User manual exists but more than 93\% people does not read the manual or try by themself.

- User feels comfortable with the legacy system or without the system at all. 
- User has little reason to use the system since they are too busy with the others job.

- Different user skill makes the adoption sluggish for the entire organization.

- User has not much time to learn and to explore the system when they are inside of working hours.

Based on these issues, this research will make an effort to improve the ICT system adoption by doing a several activities such as:

- Engage the user personally using self-paced multimedia learning.

- Creating an Instruction design model (IDM) for the organization.

- Creating several learning plan for several different people based in their existing skill.

In this research, we found that our proposed model can improve the learning curve of the user. It shows that the Live@edu usages increase by $27 \%$ after we applied the Instructions Design Model (IDM) through multimedia learning. In the next Section, we will discuss about the previous researches that related with our findings.

\section{PREVIOUS RESEARCHES}

Carliner [5] proposes an instructions design model (IDM) process that contains several phases that are definition phase, design phase, development phase, and implementation phase. These phases are designed to ensure that the e-learning is well tested and can be used independently. Table I shows the phase purposes.

TABLE I. IDM PURPOSES

\begin{tabular}{|l|ll|}
\hline \multicolumn{1}{|c|}{ Phase } & \multicolumn{1}{c|}{ Purposes } \\
\hline Definition & • & Conducting a need analysis \\
& - & Settings goal \\
& - & Preparing the need of analysis report \\
\hline Design & $\bullet$ & Choosing the form of E-learning \\
& - & Developing the learning strategy \\
& - & Establishing guidelines \\
\hline Development & - & Drafting the E-learning program \\
& - & Receiving feedback of E-learning \\
& - & Revising the E-learning \\
\hline Implementation and & $\bullet$ & Producing and distributing the E- \\
Maintenance & & learning program \\
& $\bullet$ & Promoting the E-learning \\
& - & Maintaining the E-learning program \\
\hline
\end{tabular}

In Carliner research, it is found that the IDM provides a sufficient guidance to build generic E-learning system. Generic E-learning is usually used for schools and universities. It contains curriculum, course contents, practices, and course evaluation and student profile. However, the IDM model is rarely used in an organization. This is because the company needs is different with the needs of the academic world. Company focused e-learning as a tool to increase not only the knowledge but also their productivity.
An implementation of IDM model in organization is done by O'Brien and Hall [8] by constructing a model called Training Need Analysis (TNA). It is shown that before an organization creates the e-learning they should enable companies to identify areas where their employees require training. The research provides generic TNA tools that are dedicated for SMEs allowing them to identify training requirements and assisting them to specify their own elearning content in a structure. The tool implicitly shows that to create an effective e-learning, it needs to align with the organization need through modeling rule analysis and design e-learning content.

The research about modeling rule analysis and design in Elearning content is done by Kim and Choi [10]. In the research, it shows that the usage a SCORM model as content aggregation and design model that can be the foundation to design and develop learning management system and contents.

The development of learning management and e-learning focused in several initiatives that are related in content, type of e-learning and deliverable model. Table II display the previous researches that related with E-learning development that related with an organization.

TABLE II. RELEVANT RESEARCH IN E-LEARNING DEVELOPMENT IN AN ORGANIZATION

\begin{tabular}{|c|c|}
\hline Authors & Research Topic \\
\hline Teo and Gay [6] & $\begin{array}{l}\text { A prototype system that performs a subset of } \\
\text { functions (learner profiling, knowledge } \\
\text { visualization, and learning route mapping) is } \\
\text { being developed }\end{array}$ \\
\hline Stephenson, et al [9] & $\begin{array}{l}\text { Building a specific e-learning for an } \\
\text { organization called KaryoLab. KaryoLab } \\
\text { contains background, tutorial, practice, and } \\
\text { assessment }\end{array}$ \\
\hline Schiaffino, et al [14] & $\begin{array}{l}\text { an adaptive hypermedia system that uses the } \\
\text { adaptability concept with the aim of providing } \\
\text { the same content to different students groups }\end{array}$ \\
\hline Ferretti, et al [13] & $\begin{array}{l}\text { Building an E-learning system called We- } \\
\text { Lcome. We-LCoME aim is to mashup } \\
\text { compound multimedia potentials with the so } \\
\text { called "collective intelligence" which the new } \\
\text { Web } 2.0 \text { has revealed. Final e-learning media } \\
\text { by using SMIL }\end{array}$ \\
\hline Moller, et al [7] & $\begin{array}{l}\text { An integrative concept for information and } \\
\text { communication technology (ICT) supported } \\
\text { education in modeling and simulation }(\mathrm{M} \& S) \text {. } \\
\text { The implementation of the M\&S program } \\
\text { uses ICT as an indispensable part of the } \\
\text { modern education system. }\end{array}$ \\
\hline
\end{tabular}

Based on the previous researches that described in Table II, it shows that the development E-learning in an organization should focus on:

- The specific need of the user in an organization. The elearning initiative is done by creating custom application that delivers specific learning experiences.

- $\quad$ Building the system with multimedia and collaboration standard such as web 2.0 or SMIL.

- Profiling the user based on their skill, knowledge gap, and learning plan. 
The last step on the IDM model is the implementation and maintenance phase of E-learning, also called as an adoption phase. This phase is critical path of the E-learning adoption. Table III Shows The Related Research That Focuses In ELearning Adoption.

TABLE III. RELEVANT RESEARCH IN E-LEARNING ADOPTION

\begin{tabular}{|l|l|}
\hline \multicolumn{1}{|c|}{ Authors } & \multicolumn{1}{c|}{ Research Topic } \\
\hline Mesomela and & $\begin{array}{l}\text { The study that covers usability evaluation or } \\
\text { an examination of the user interface of an e- } \\
\text { learning product and usage analysis of an e- } \\
\text { learning application designed to support } \\
\text { learning in a cognitive domain }\end{array}$ \\
\hline $\begin{array}{l}\text { Luojus and Vilkki } \\
{[13]}\end{array}$ & $\begin{array}{l}\text { The pedagogical starting point for developing } \\
\text { instruction in digital media was to produce } \\
\text { new competence. The outcome of the } \\
\text { development work was a teaching model that } \\
\text { follows the user-driven design process, with } \\
\text { the aim of providing students with the ability } \\
\text { to act as developers of product development } \\
\text { and innovation processes in their fields }\end{array}$ \\
\hline Bang [19] & $\begin{array}{l}\text { Integrate Multimedia Digital AP Server to } \\
\text { provide immediate self-help and } \\
\text { strengthening materials to students so that } \\
\text { students can focus on the part they needed to } \\
\text { be strengthened among extensive pool of } \\
\text { books, thus helping learners to enhance the } \\
\text { fun and efficiency of learning }\end{array}$ \\
\hline Mehlenbacher, et al & $\begin{array}{l}\text { The research reviews 300 e-learning journal } \\
\text { and one of the related point of view is about } \\
\text { how Web Based Interface provide sufficient } \\
\text { interface to learn effectively }\end{array}$ \\
\hline 3$]$
\end{tabular}

Based on the research that described in Table III, it shows that the adoption of the E-learning depends on:

- The timeframe of the adoption. It is shown that the quick adoption make the participant should learn more intensively. The technology such as web provides a flexible way to learn.

- The usage of a skill that delivered in E-learning. It is shown that a skill that related with the daily work of an organization lead to a quick adoption on the organization E-learning.

- Contextual and learning plan selection. Several researches show that effective e learning need align with content design based on the user need.

It is found that the implementation E-learning for an organization to learn something or to adopt anything is different with the implementation E-learning in the university or academic learning. Based on the previous researches, it shows that the E-learning in organization should have unique approach to achieve the benefits.

\section{THEORETICAL BACKGROUND}

As mentioned before, the purposes of the research is to create a learning plan for any organization who wants to adopt ICT system through E-learning model. Based on previous researches, it shows various approaches to learn and adopt Elearning in an organization. In this research, it is chosen that the research will use the IDM model. The IDM model is chosen because:
- IDM model is mature enough and has been proven in academic and industry. [1] [4] [5] [11]

- IDM model provides complete engineering process for E-learning lifecycle.

- IDM can be pattern matched with a software development lifecycle (SDLC). It has similar phases such as requirement, analysis-design, development, and deployment [17]. Table IV shows the pattern matching between IDM phase and SDLC.

TABLE IV. IDM AND SDLC PATTERN MATCHING

\begin{tabular}{|l|l|l|}
\hline \multicolumn{1}{|c|}{ IDM Phases } & \multicolumn{1}{|c|}{$\begin{array}{c}\text { SDLC Phases } \\
\text { (V\&V) }\end{array}$} & \multicolumn{1}{c|}{ Similarity } \\
\hline Definition & $\begin{array}{l}\text { Requirements } \\
\text { Engineering }\end{array}$ & $\begin{array}{l}\text { Providing a detail step to } \\
\text { refine the purposes, to } \\
\text { select the technology, to } \\
\text { collect the need of a } \\
\text { system }\end{array}$ \\
\hline Design & Design & $\begin{array}{l}\text { Providing a several action } \\
\text { to design the system }\end{array}$ \\
\hline Development & Development & $\begin{array}{l}\text { Modification, construct, } \\
\text { and installing the system }\end{array}$ \\
\hline $\begin{array}{l}\text { Implementation } \\
\text { and Maintenance }\end{array}$ & $\begin{array}{l}\text { Testing and } \\
\text { Implementation }\end{array}$ & $\begin{array}{l}\text { User acceptance testing } \\
\text { and system socialization. }\end{array}$ \\
\hline
\end{tabular}

Table IV shows that both IDM and SDLC has several similarities. The similarity leads the research to create a research phases that combined both phases. The great combination focuses in the last phase that is implementation.

In the implementation phase, the SDLC phase focuses in User Acceptance Test (UAT). UAT in software engineering provides several activities that dedicated for the properness of the created system with the user. The proposed system should meet its business requirements and to provide confidence that the system works correctly and is usable before it is formally "delivered" [18]. UAT should also address the testing of system documentation.

The IDM also bring the UAT in the first class testing with addition system socialization. When the proposed system meets the business need, the next challenge is to adopt the system to the existing environment. In this step, IDM provides step to promote E-learning. Based on that fact, we strongly believe that the IDM and SDLC give sufficient lifecycle to adopt ICT system. Both phases provide complete lifecycle in ICT development and adoption. In this research, we focus in the adoption only because several reasons such as:

- The system is already built by a software vendor. Therefore, it has no need to do full lifecycle step in SDLC. It just needs focus in IDM phase.

- The system is a common system for ICT Communication. In this research, the system is a full suite of communication platform such as email, online storage, and PIM software. Therefore, it will no need special training or long workshop.

- The adopted system has a previous similar system. Therefore, some user feels comfortable with the 
existing system and need a good reason to use the new system.

Based on that reasons, it will start the research by creating adoption plan, constructing the learning model, and evaluating the learning model.

\section{ADOPTION PLANNING}

The adoption plan starts with the implementation of the system. Since, the ICT system is Software as a Services solution the implementation simply as activating the services, enrolling the user and testing the services availability. Figure 1 show the research phase that designed based on the combination of both.

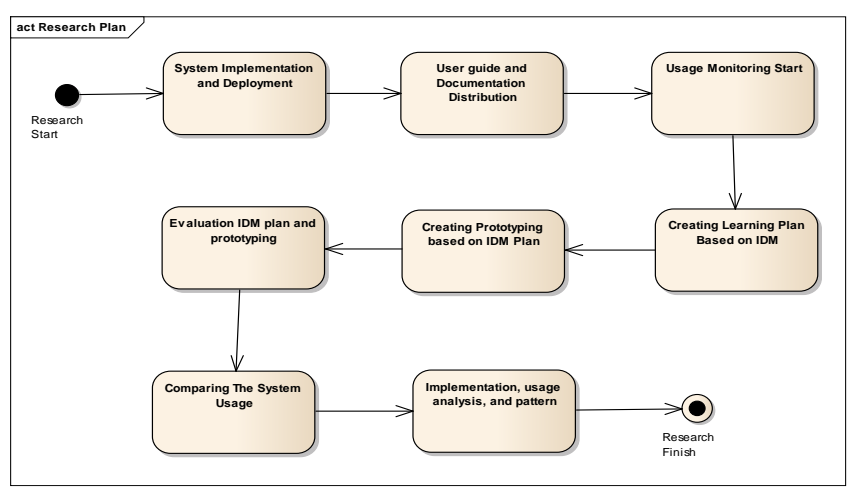

Figure 1. Research Phase

After doing implementation in the new system, the research starts from conventional adoption strategies which are the distribution of documentation and guidance. At this point, the organization stakeholder creates a memo to the employees to use the system. The memo enriches with manual and user guide for the system usage. In this case, the research prepares the instrumentation system to evaluate the usage of the system. Fortunately, the proposed system has out of the box-reporting feature called account trend. Account trend covers provisioned and active account. Provisioned account is the numbers of enrollment account. Active account is the numbers of active user that use the services. By dividing the active account with the provisioned account the research declares the active usage index. The active usage index will have a value between 0.00 -1.00 . The closer to the 1.00 the better value to the for active usage index. Figure 2 shows the reporting features in the proposed system.

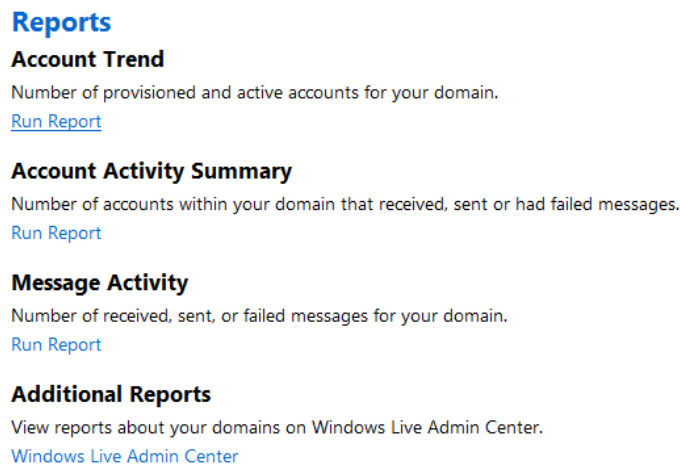

Figure 2. Active ID Excerpt Sample
The active usage index will be the main evidence for the research result. The active usage index will be calculated manually on this research. The active usage index will be measured before and after the treatment. As mentioned before, the treatment step is started by creating a learning model that described in Section V. The learning model implementation report will be discussed in Section VI.

\section{CONTSRUCting A LEARNING Model}

In this research, it is assumed that the learning model is an approach to deliver good e-learning experience. It covers behavior of user, content learning plan, and socialization technique. With a scope that the main focus of the training is quickly adopt a new ICT system. The proposed learning model is constructed by doing several activities such as:

- Observing to the organization and see what they use and like in the existing system.

- Meeting with the stakeholder what they think and they hope with the new system.

- Classifying the learning item based on the need of the organization

- Creating the learning plan based on the system features classification.

- Creating learning content based on the learning plan.

- Distributing learning content based on the discussion within the stakeholder.

The observation activity covers a set of action that engages between implementation team with the client. In this step, it is done by using formal discussion and quick pool. Formal discussion did a quick observation about daily activity of the employee organization. Fifty employees join the session. The research does patterns matching between their daily activity with the proposed ICT system. Table V shows the system features and the usage scenarios that related with the organization business process. The system features is ranked by the result of quick pool.

TABLE V. System Features And Usage Scenarios Patterns MATCHING

\begin{tabular}{|l|l|l|}
\hline System Features & \multicolumn{1}{|c|}{ Usage Scenarios } & Priority \\
\hline Email & $\begin{array}{l}\text { Business Communication, Internal } \\
\text { memo, business letter }\end{array}$ & High \\
\hline Calendar & internal meeting schedule & High \\
\hline Task & $\begin{array}{l}\text { Assignment memo from supervisor } \\
\text { to emplooye }\end{array}$ & Medium \\
\hline Online Storage & $\begin{array}{l}\text { Storing digital multimedia content } \\
\text { such as document and e-learning } \\
\text { content }\end{array}$ & Medium \\
\hline $\begin{array}{l}\text { Public Address } \\
\text { Book }\end{array}$ & Organization contact repository & Medium \\
\hline Instant Messaging & Quick chat & Low \\
\hline
\end{tabular}

The priority is concluded from a quick pool in the discussion session. Each participant will select the priority (high medium and low). If $70 \%$ participants select the same priority, the feature will have the selected priority. It is shown that email and calendar are the most demanded features in the organization. The result of the quick pool and discussion is 
summarized and presented to the stakeholders in stakeholder gathering session.

Stakeholder gathering session establishes a shared vision between implementation team and stakeholder. In this research, the stakeholder gathering sessions discuss several items that are:

- An initial report that is obtained from the observation session.

- A feedback sharing session that is come from the stakeholder about the new system.

- The current activity and problem that might be solved by the new system

- Short discussion about the challenge that might be or already happen when adopting the new system.

- The milestone plan that will be adopted to implement new system.

Table VI summarizes the result of the gathering session with the stakeholder. It shows the problems, approaches, and the milestone when the problems and approaches is executed.

TABlE VI. Milestone, Problem, And Approach Planning

\begin{tabular}{|c|c|c|}
\hline Milestone & Problem Addressed & Approaches \\
\hline \multirow[t]{4}{*}{$\begin{array}{l}\text { Piloting } \\
\text { Phase }\end{array}$} & $\begin{array}{l}\text { Not all full time } \\
\text { employees already } \\
\text { enrolled to the system }\end{array}$ & $\begin{array}{l}\text { Mass registration to the } \\
\text { system }\end{array}$ \\
\hline & $\begin{array}{l}\text { Employees do test drive } \\
\text { the new system without } \\
\text { manual }\end{array}$ & $\begin{array}{l}\text { User guide and quick } \\
\text { reference card is distributed } \\
\text { using online storage channel }\end{array}$ \\
\hline & $\begin{array}{l}\text { The user guide and quick } \\
\text { manual won't be read } \\
\text { during the business of } \\
\text { the employee }\end{array}$ & $\begin{array}{l}\text { Building a short tutorial } \\
\text { rather than user guide }\end{array}$ \\
\hline & $\begin{array}{l}\text { Employees are confused } \\
\text { to import their existing } \\
\text { work into the new } \\
\text { system }\end{array}$ & $\begin{array}{l}\text { Building a tutorial how to } \\
\text { migrate the current work } \\
\text { into the new system }\end{array}$ \\
\hline \multirow[t]{2}{*}{$\begin{array}{l}\text { Adopting } \\
\text { Phase }\end{array}$} & $\begin{array}{l}\text { The new system } \\
\text { adoption should be also } \\
\text { adopted by the client and } \\
\text { customer. }\end{array}$ & $\begin{array}{l}\text { Enrolling and distributing } \\
\text { key access of the system }\end{array}$ \\
\hline & $\begin{array}{l}\text { The impossibility to do } \\
\text { socialization and } \\
\text { workshop for more than } \\
1000 \text { clients and } \\
\text { customers }\end{array}$ & $\begin{array}{l}\text { Building an e-learning } \\
\text { portal that can be accessed } \\
\text { online }\end{array}$ \\
\hline
\end{tabular}

Table VI shows that the learning model should covers three main approaches for learning which are building short tutorial for daily usage, building short tutorial for migrating a system, and building a learning portal for remote consumer. The three activities contents are structured by the team in an internal meeting.

The internal meeting classifies the main structure of the leaning model. The structure is composed by considering several items which are:

- The employees have several information assets in the existing system. Therefore, the first learning structure should cover a migration strategies and guidelines.
- The employees should know the main part of the application that related with their daily business activity. Therefore, after the migration the employee should learn the system features based on priority that already described in Table V.

- The remote users such as client and consumer should learn how to use e-learning portal that will be deployed as an approach to make the new system could be used by the entire organization.

Figure 3 shows the learning plan that will be used as a framework for the learning content. Migration learning focuses to cover any actions that should be done to migrate from existing to new system. Essential learning phase covers the essential topic that have to be mastered to use the system. Enhancement learning phase is a continuous phase that will be updated regularly. The enhancement learning phase will cover additional topic that not covered by the essential learning phase. In this step, the implementation learning phase will be executed in three months.

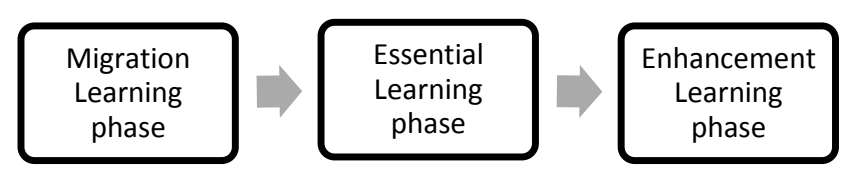

Figure 3. Learning Phases For Implementing ICT System

Each phase will have several contents based on the discussion within stakeholder and the 50 main users. Table VII describes the learning content in every phase.

TABLE VII. Milestone, PROBLEM, AND APPROACH PLANNING

\begin{tabular}{|c|c|}
\hline $\begin{array}{c}\text { Learning } \\
\text { Phase }\end{array}$ & Learning Topic \\
\hline $\begin{array}{l}\text { Migration } \\
\text { Learning }\end{array}$ & $\begin{array}{l}\text { - } \begin{array}{l}\text { Migrating the address book of the existing system } \\
\text { - }\end{array} \text { Archiving the old email and conversation } \\
\text { Archiving and converting the document to prepare } \\
\text { the online storage }\end{array}$ \\
\hline $\begin{array}{l}\text { Essential } \\
\text { Learning }\end{array}$ & $\begin{array}{ll}- & \text { Basic email configuring with Outlook Web } \\
& \text { Access (OWA) } \\
\text { - } & \text { Downloading and managing email through } \\
& \text { Outlook client } \\
\text { - } & \text { PIM management using OWA } \\
\text { - } & \text { Instant messaging in OWA } \\
\text { - } & \text { Office productivity using Office Web Apps } \\
\end{array}$ \\
\hline $\begin{array}{l}\text { Enhancem } \\
\text { ent } \\
\text { Learning }\end{array}$ & $\begin{array}{ll}\text { - } & \text { Accessing an email in a limited connection } \\
\text { - } & \text { Sharing and managing the online storage in } \\
\text { SkyDrive } \\
\text { - } \\
\text { Accessing and connecting other system through } \\
\text { OWA } \\
\text { - }\end{array}$ \\
\hline
\end{tabular}

After the creation of the learning plan, implementation team to create an ad-hoc team that focuses to develop the learning content. The team is composed three persons namely instruction design mentor and two talents. The instruction design mentor creates the tutorial scenarios. The tutorial itself works as a demo driven tutorial. After the scenario is created, the design mentor will propose the scenario to be recorded by the talents. The tutorial output is composed as three main outputs that are slide deck presentation, recorded video, and 
demo script document. The outputs will be uploaded to the Elearning portal. The implementation of the E-learning content and the socialization of e-learning portal will be described in Section VI.

\section{LEARNING MODEL IMPLEMENTATION}

The learning model implementation is aligned with the ICT implementation phase. The implementation model is done through two phases which are internal phase and external phase. Internal phase focuses in implementation activity in internal organization. It contains 100 employees that work permanently onsite in the organization. The external phase focuses implementation in external organization such as customer, alumni, community, and remote workers. It reaches 1500 persons that are separated geographically around Java, Sumatra, and Kalimantan.

Learning implementation in internal phase is done through blended learning. The blended learning contains an onsite workshop and self-paced online learning. Onsite workshop contains any material that related with essential learning that described in Table VII. On the other hand, the online learning is done by using organization online storage that stored in the new system. The online learning works as follow:

- The learning contents are uploaded into an online storage that parts of the new system. There are seven video lessons that uploaded and ready to view as selfpaced e-learning.

- The learning contents link is distributed by the ICT supervisor in the organization. The link is distributed through a new email system.

- The learning content has a playlist as a step-by-step recommendation to learn the essential features of the system. Figure 4 shows the video playlist.

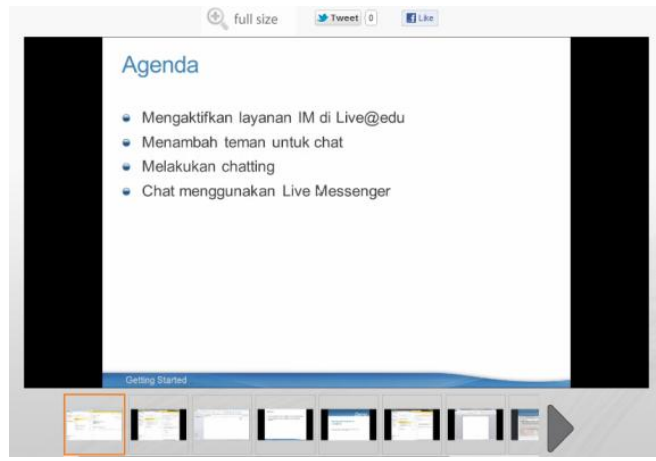

Figure 4. Video Playlist For Self-Paced E-Learning

The internal phase implementation model enhances the usages of the system by $27 \%$ for the first month. After that, the increment of the system usage is between $20-25 \%$ and it is reached to use by the entire employees in the fourth months.

The external phase implementation is started two months after the internal phase is started. The external phase focuses in three main activities which are:
- Building and configuring online E-learning that can be accessed through the web. Figure 5 shows the E-online learning that exposed to the external users.

- Collaborating and engaging the local community leader to learn and to acknowledge the others peers about online E-learning.

- The online E-learning contains the entire E-learning topic that is described in Table VII.

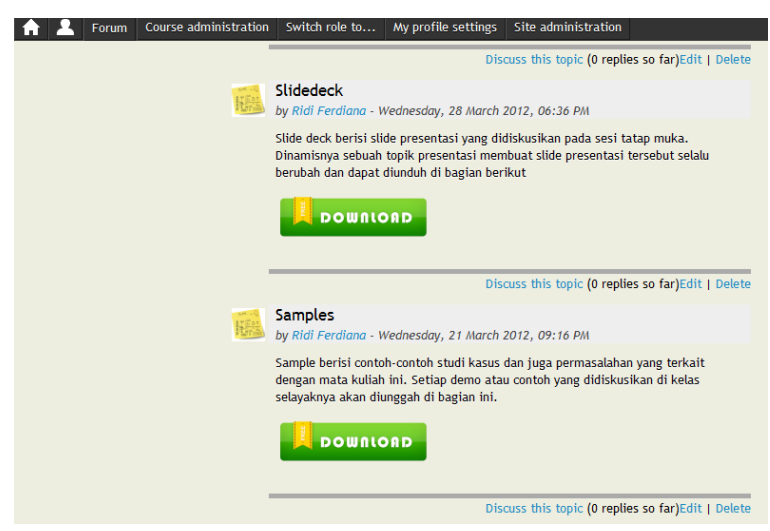

Figure 5. Online E-Learning For External Implementation Phase

The external phase implementation increases the usages of the system by $5 \%$ for the first week. The thousand numbers of users that separated in geographically make the implementation slower. Therefore, the further implementation and the usage of the new system are much depends with the local community leader. Therefore, the external phase implementation is still executed as a part of regular activity in the organization.

Table VIII shows the overall adoption that reach $27 \%$ average improvement using the proposed method. The percentage is calculated by counting the system usage in four months. The calculation compares between before and after adopting the ICT-IDM method. The percentage is calculated from the number of active user divides by the total user. The implementation phase in the table shows the total users based on external and internal phase for four months.

TABLE VIII. USAGE TABLES

\begin{tabular}{|l|c|c|c|}
\hline System Features & $\begin{array}{c}\text { Initial Phase } \\
\text { (Before } \\
\text { Adopting The } \\
\text { ITC-IDM) }\end{array}$ & $\begin{array}{c}\text { Implementation } \\
\text { phase (After } \\
\text { Adopting The } \\
\text { ICT-IDM) }\end{array}$ & $\begin{array}{c}\text { Improvement } \\
\text { Usage }\end{array}$ \\
\hline Email & $13 \%$ & $76 \%$ & $63 \%$ \\
\hline Calendar & $2 \%$ & $23 \%$ & $21 \%$ \\
\hline Task & $0 \%$ & $21 \%$ & $21 \%$ \\
\hline Online Storage & $5 \%$ & $38 \%$ & $33 \%$ \\
\hline $\begin{array}{l}\text { Public Address } \\
\text { Book }\end{array}$ & $3 \%$ & $16 \%$ & $13 \%$ \\
\hline Instant Messaging & $0 \%$ & $13 \%$ & $13 \%$ \\
\hline $\begin{array}{l}\text { Improvement } \\
\text { average }\end{array}$ & & & $27 \%$ \\
\hline
\end{tabular}

\section{DISCUSSION AND FURTHER WORK}

In this research, it is started with believe that a new ICT system that developed is not used optimally. Therefore, the research creates an initiative to do further ICT system 
socialization by adopting e-learning initiative using IDM approaches. The research discovers several techniques and approaches to increase the new ICT system adoption such as follows.

- Closer Communication to the users and the stakeholder. This technique creates a clear view for the bottleneck and the real problem that exist in the ICT system implementation.

- Incremental adoption plan. This technique is done by doing implementation through three milestone phases. Each phase addresses the specific problem and approaches.

- Problem driven learning development. This technique is done by creating a learning development through several learning phases namely migration learning, essential learning, and enhancement learning. These learning phases use instruction design model

- Multimedia e-learning development. This technique is done by adopting IDM through multimedia e-learning content. Video, demo script and slide deck. The contents are uploaded into online storage to reach the users. The multimedia e-learning provides self-paced e-learning to decrease the skill gap between users by providing flexible way to learn the system.

- Iterative learning implementation. This technique is done by using two phases of the implementation which are external and internal phase. Both phases use iterative and continuous improvement model to increase the usage and the system adoption.

The techniques still has future work since the ICT-IDM only increase the system usage for just $27 \%$. The hardest part is to socialize to the external organization. Therefore, it needs further improvement to eliminate geographical problem, huge numbers of user, and different skills of the users. The global model of the ICT-IDM adoption should be proposed for the further work of the research.

\section{ACKNOWLEDGMENT}

We thank Partners in learning program that supports this research initiative. Microsoft Innovation Center UGM people and the ICT people at P4TK Mathematic organization that provided a helpful insight and approaches to do this research.

\section{REFERENCES}

[1] Allen, Michael W. 2007. Designing Successful e-Learning: Forget What You Know about Instructional Design and Do Something Interesting, Michael Allen's e-Learning Library. Pfeiffer.

[2] Bernard R. Gifford and Noel D. Enyedy. 1999. Activity centered design: towards a theoretical framework for CSCL. In Proceedings of the 1999 conference on Computer support for collaborative learning (CSCL '99), USA.

[3] Brad Mehlenbacher, Krista Holstein, Brett Gordon, and Khalil Khammar. 2010. Reviewing the research on distance education and elearning. In Proceedings of the 28th ACM International Conference on Design of Communication (SIGDOC '10). ACM, New York, USA.

[4] Carliner, Saul, and Patti Shank (eds). 2008. The e-Learning Handbook: Past Promises, Present Challenges. Pfeiffer.

[5] Carliner, Saul. 2002. Designing E-learning. ASTD. USA. 978-1-56286$332-6$.
[6] Chao Boon Teo and Robert Kheng Leng Gay. 2006. A knowledgedriven model to personalize e-learning. J. Educ. Resour. Comput. 6, 1, Article 3 (March 2006).

[7] Dietmar P. F. Möller and Hamid Vakilzadian. 2010. Integrating modeling and simulation into an e-learning environment in engineering study programs. In Proceedings of the 2010 Conference on Grand Challenges in Modeling \& Simulation (GCMS '10). Society for Modeling \& Simulation International, Vista, CA, 90-97.

[8] Emma O'Brien and Timothy Hall. 2004. Training Needs Analysis: the first step in authoring e-learning content. In Proceedings of the 2004 ACM symposium on Applied computing (SAC '04). ACM, New York, NY, USA, 935-939.

[9] JE Stephenson, WB Morris, HG Tempest, DK Griffin, A Mileham, and AM Payne. 2007. The use of an e-learning constructivist solution in workplace learning. In Proceedings of the 14th European conference on Cognitive ergonomics: invent! explore! (ECCE '07).

[10] Jin-Sung Kim and Kwang-Jin Choi. 2009. Modeling rule for analysis and design of e-learning content. In Proceedings of the 2009 International Conference on Hybrid Information Technology (ICHIT '09). ACM, New York, NY, USA, 353-360.

[11] Rothwell, William J., and H.C. Kazanas. 2008. Mastering the Instructional Design Process: A Systematic Approach, Fourth Edition. Pfeiffer.

[12] S. S. (Thabo) Masemola and M. R. (Ruth) De Villiers. 2006. Towards a framework for usability testing of interactive e-learning applications in cognitive domains, illustrated by a case study. In Proceedings of the 2006 annual research conference of the Souuth African institute of computer scientists and information technologists on IT research in developing countries (SAICSIT '06), Judith Bishop and Derrick Kourie (Eds.). South African Institute for Computer Scientists and Information Technologists, , Republic of South Africa, 187-197.

[13] Satu Luojus and Olli Vilkki. 2008. Development of user-driven research methods as the starting point for living lab activities. In Proceedings of the 5th Nordic conference on Human-computer interaction: building bridges (NordiCHI '08). ACM, New York, USA.

[14] Silvia Schiaffino, Analía Amandi, Isabela Gasparini, and Marcelo S. Pimenta. 2008. Personalization in e-learning: the adaptive system vs. the intelligent agent approaches. In Proceedings of the VIII Brazilian Symposium on Human Factors in Computing System.

[15] Stefano Ferretti, Silvia Mirri, Ludovico Antonio Muratori, Marco Roccetti, and Paola Salomoni. 2008. E-learning 2.0: you are WeLCoME!. In Proceedings of the 2008 international cross-disciplinary conference on Web accessibility (W4A) (W4A '08). ACM, New York, USA

[16] Tsui, Frank \& Karam, Orlando. 2011. Essentials of software engineering, second edition. Jones and Bartlett Publishers.

[17] Vliet, Hans van. 2008. Software Engineering: Principles and Practice, Third Edition. John Wiley \& Sons.

[18] Watkins, John \& Mills, Simon. 2011. Testing it: an off-the-shelf software testing process, 2nd edition. Cambridge University Press.

[19] Yao Chin-Bang. 2009. Context-aware customization e-learning system with intelligent on-line examination mechanism. In Proceedings of the 2nd International Conference on Interaction Sciences: Information Technology, Culture and Human (ICIS '09). ACM, New York, USA.

\section{AUTHORS PROFILE}

Ridi Ferdiana. got his doctoral degree at Universitas Gadjah Mada in 2011. $\mathrm{He}$ earned his master degree from the same university in 2006. In his professional area, he holds several professional certifications such as MCP, MCTS, MCPD, MCITP and MCT. In his daily research activities he really enjoys to learn about software engineering, business platform collaboration, and programming optimization. He can be reached at ridi@acm.org.

Obert Hoseanto is the Partners in Learning Manager of Microsoft Indonesia, based in Jakarta, Indonesia. His research interests are educational technology, e-learning and teacher education, and can be contacted at obert.hoseanto@microsoft.com. 